\title{
Brain oxytocin: how puzzle stones from animal studies translate into psychiatry
}

\author{
Valery Grinevich $\mathbb{D}^{1} \cdot$ Inga D. Neumann $\mathbb{D}^{2}$
}

Received: 10 February 2020 / Revised: 14 May 2020 / Accepted: 27 May 2020 / Published online: 8 June 2020

(c) Springer Nature Limited 2020

\begin{abstract}
The neuropeptide oxytocin has attracted great attention of the general public, basic neuroscience researchers, psychologists, and psychiatrists due to its profound pro-social, anxiolytic, and "anti-stress" behavioral and physiological effects, and its potential application for treatment of mental diseases associated with altered socio-emotional competence. During the last decade, substantial progress has been achieved in understanding the complex neurobiology of the oxytocin system, including oxytocinergic pathways, local release patterns, and oxytocin receptor distribution in the brain, as well as intraneuronal oxytocin receptor signaling. However, the picture of oxytocin actions remains far from being complete, and the central question remains: "How does a single neuropeptide exert such pleotropic actions?" Although this phenomenon, typical for many of about 100 identified neuropeptides, may emerge from the anatomical divergence of oxytocin neurons, their multiple central projections, distinct oxytocin-sensitive cell types in different brain regions, and multiple intraneuronal signaling pathways determining the specific cellular response, further basic studies are required. In conjunction, numerous reports on positive effects of intranasal application of oxytocin on human brain networks controlling socio-emotional behavior in health and disease require harmonic tandems of basic researchers and clinicians. During the COVID-19 crisis in 2020, oxytocin research seems central as question of social isolation-induced inactivation of the oxytocin system, and buffering effects of either activation of the endogenous system or intranasal application of synthetic oxytocin need to be thoroughly investigated.
\end{abstract}

\section{Introduction}

A large number of neuropeptide systems have emerged as viable regulators of multiple facets of socio-emotional or motivational behaviors and, thus, as potential treatment targets for psychopathologies, such as anxiety, autism spectrum, and substance use disorders, schizophrenia or major depression, among others. Among the about 100 identified neuropeptides (http://www.neuropeptides.nl) only

Valery Grinevich

valery.grinevich@zi-mannheim.de

$\triangle$ Inga D. Neumann

Inga.Neumann@ur.de

1 Department of Neuropeptide Research in Psychiatry, Central Institute of Mental Health, Medical Faculty Mannheim, University of Heidelberg, 68159 Mannheim, Germany

2 Department of Neurobiology and Animal Physiology, University of Regensburg, 93040 Regensburg, Germany few of them currently attracted scientific attention, which include the nonapeptides oxytocin (OXT) [1-3] and arginine vasopressin (AVP) [2, 4, 5], corticotropin releasing factor [6], neuropeptide $\mathrm{Y}$ [7], neuropeptide S [8-10], VIP/PACAP [11], and cholecystokinin-octapeptide [12]. Although promising behavioral effects in health and disease have been described, most of these neuropeptide systems will hardly become a serious treatment target either due to lack of clinical efficacy of developed agonists or antagonists, or reported side effects in animals or in clinical trials.

In contrast, with synthetic OXT being already used in obstetric medicine for more than 50 years, a safe neuropeptide is available. Profound anxiolytic, anti-stress, and a plethora of pro-social effects of endogenous or synthetic OXT have not only been revealed in laboratory animals (for review see $[1,13]$ ), but also in humans, where synthetic OXT was applied intranasally (IN) $[14,15]$. With a still raising interest in the molecular and neuronal mechanisms of actions within the brain on the one side and in the behavioral and physiological effects of OXT, especially in human studies, on the other, OXT-related 
publications have increased almost double in the last 20 years ([1] Pubmed).

Here, we will provide a comprehensive overview about the neurobiology of the brain OXT system including (i) OXTergic neuronal circuitries originating in the hypothalamus, (ii) local neuropeptide release stimulated by stress, social interactions, or optogenetic and chemogenetic challenges, and (iii) OXT receptor- (OXTR) mediated intracellular signaling in neurons, which possibly underlie selected behavioral effects of OXT. Moreover, we will summarize current experimental strategies to either monitor, or to manipulate, the activity of OXT neurons and their downstream targets. We also propose some futuristic scenarios for implementation of OXT into treatment of human patients afflicted with socio-emotional disorders. Finally, we discuss the importance of the brain OXT system in times of pandemic-associated social isolation and psycho-social stress, as seen during the COVID-19 crisis in 2020 .

\section{Neuroanatomy of the OXT system}

OXT homologs, as many other neuropeptides [16], are evolutionary old regulatory molecules and appeared $\sim 700$ Mio years ago, prior Cambrian explosion [17]. In mammals, along with its closely related nonapeptide AVP, OXT is synthesized in distinct hypothalamic neurons, which form the hypothalamo-neurohypophysial system (HNS) (Fig. 1). Relatively large, i.e., magnocellular OXT (and AVP) neurons with a somatic diameter of about 20-35 $\mu \mathrm{m}$ [18] are located in the bilateral supraoptic (SON), paraventricular (PVN), and accessory nuclei of the hypothalamus (Fig. 1). These neurons project via the pituitary stalk to the neurohypophysis, where their axon terminals form neurohemal contacts with local fenestrated capillaries essential for OXT secretion into the blood

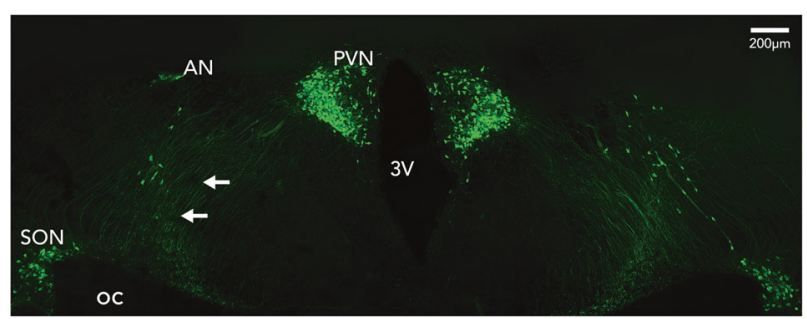

Fig. 1 Overview of the hypothalamic oxytocin nuclei. Confocal panel shows hypothalamic OXT-ergic SON, PVN, and fornical accessory nucleus (AN) of an adult male rat, stained with antibody against OXT, generously provided by Dr. Harold Gainer (NIH). Images were obtained using a Leica LSM780 confocal microscope at $10 \times$ (z-stacks, $30 \mu \mathrm{m}, 1 \mu \mathrm{m}$ steps) and realigned and merged in Adobe Photoshop. SON supraoptic nucleus, PVN paraventricular nucleus, $3 \mathrm{~V}$ third ventricle, OC optic chiasm. Arrows point towards the hypothalamic-neurohypophysial tract. stream. Due to its specific anatomy and physiology, the HNS has become a textbook example that has been studied for more than 100 years [1, 19-21]. Indeed, seminal neuroendocrine discoveries have been made using the HNS including the regulation of neuropeptide gene expression, intraneuronal processing and transport, stimulus-secretioncoupling, and intracerebral including dendritic transport and release reviewed elsewhere.

In addition to magnocellular OXT neurons, there exist smaller and fewer parvocellular neurons, which are mainly localized bilaterally within the dorsolateral subdivision of the PVN. The about 100 parvocellular OXT neurons (this number is estimated for a rat) are clearly distinct from magnocellular neurons, as they do not possess projections to the neurohypophysis; they should exclusively connect to midbrain, brain stem, and spinal cord targets [22]. Also, parvocellular PVN neurons connect to the ipsilateral SON and to the contralateral PVN, where they contact magnocellular OXT neurons to coordinate their activity [23].

Both parvocellular and magnocellular OXT neurons essentially form the brain OXT system. Thus, their projections and collaterals, respectively, provide the neuronal substrate for central, intracerebral release of OXT. In addition, dendritic trees of magnocellular OXT neurons within the SON and PVN form the basis for local somatodendritic release of OXT [24, 25]. In recent years, our understanding of the anatomical complexity of the brain OXT system and its involvement in the fine-tuned regulation of specific aspects of socio-emotional behavior has significantly increased mainly due to the advent of innovative viral vector-based tracing combined with chemo- and optogenetic techniques.

\section{Intracerebral OXT pathways and methods to reveal them}

After generation of antibodies against OXT and its carrier protein neurophysin I in the 1980's [26], numerous studies have focused on the identification of OXT-immunoreactive fibers throughout the brain. Although detectable immunosignal in distant OXT axons were found in several hindbrain regions [27], the detection of OXT immunoreactivity in axons of forebrain regions were limited to only a few structures, such as the tenia tecta, lateral septum [28], and the nucleus accumbens [29]. However, a more recent finding employing soluble genetically encoded fluorescent markers reported the spread of OXT axons through about 50 forebrain regions of rats in addition to their major projections to the neurohypophysis [30]. Collaterals of magnocellular OXT neurons of both the PVN and SON project to the medial and central amygdala, lateral septum, prefrontal cortex, anterior olfactory nucleus, and nucleus accumbens 
[17, 31-33], where these projections were validated not only anatomically, but also functionally (Fig. 2) (for review see [30]).

Evidence for the existence of such functionally specialized OXT neurons has been very recently provided by genetic labeling of OXT neurons activated during fear expression in rats [34]. Although the number of labeled OXT neurons corresponded to only $\sim 10 \%$ of all magnocellular OXT neurons, their activation or silencing resulted in attenuation or elevation of fear behavior, respectively. These "fear-sensitive" OXT cells almost exclusively project to the central nucleus of amygdala - the hub region of fear response.

However, the number of centrally projecting OXT axon collaterals is in general rather low [30], which may explain, why these fibers containing a limited OXT-immunoreactive product (e.g., the number of OXT "puncta") were simply overlooked in the past. For example, using retrogradely transmitted virus CAV2, we could identify about 25 magnocellular OXT neurons of the SON, and about 5 neurons of the PVN projecting to the lateral septum of lactating mice [33]. These OXT cells were classified as magnocellular based on their labeling by systemically delivered Fluorogold, which is exclusively taken up by axonal terminals in regions lacking a blood-brain barrier, such as the neurohypophysis.

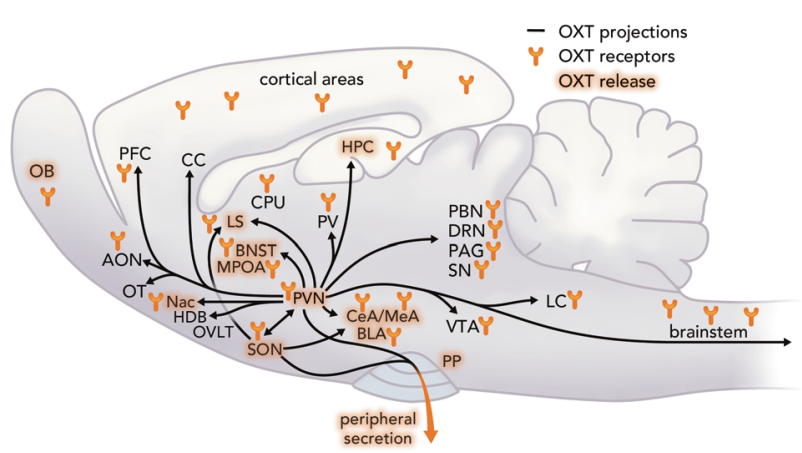

Fig. 2 Scheme of a sagittal view on a rat brain including OXT neuronal projections, OXT release and OXTR binding within brain target regions. This scheme summarizes all available data from male and female including lactating rats regarding OXT neuronal projections, sites of OXT release, e.g., during stress exposure, mating, parturition, suckling, and OXT receptors within brain target regions, as outlined in detail in the text. AON anterior olfactory nucleus, OB olfactory bulb, OT olfactory tubercle, Nac nucleus accumbens, OVLT organum vasculosum laminae terminalis, SON supraoptic nucleus, PVN paraventricular nucleus, PP posterior pituitary, PFC prefrontal cortex, CC cingulate cortex, MPOA medial preoptic area, BNST bed nucleus of the stria terminalis, LS lateral septum, $\mathrm{CPu}$ caudate putamen, $\mathrm{PV}$ periventricular nucleus of the thalamus, CeA central amygdala, MeA medial amygdala, BLA basolateral amygdala, VTA ventral tegmental area, LC locus coeruleus, PBN parabrachial nucleus, DRN dorsal raphe nucleus, PAG periaqueductal gray, SN substantia nigra, HPC hippocampus, HDB nucleus of the horizontal limb of the diagonal band. Adapted with allowance from [1].
Of note, parvocellular OXT neurons remain negative for Fluorogold labeling as they do not form axo-vascular contacts with blood vessels in the neurohemal region of the neurohypophysis [35]. This cell type of OXT neurons largely extends their axons to the hindbrain, although their projections to the forebrain regions have not been elaborated so far [36]. However, a recent genetic profiling of OXT neurons [37] resulted in the identification of 5 types of OXT cells, which probably represent subpopulations of magno- and parvocellular OXT neurons, potentially projecting to hindbrain [38] and forebrain, respectively.

The above described OXT axonal connections throughout the brain form the neuroanatomical substrate of OXT release in the respective brain target regions. With respect to the dynamics of OXT release into blood and within distinct brain regions, we have to keep in mind that magnocellular OXT neurons, which are mainly characterized by their projections to the neurohypophysis, may or may not collectively respond with release within central target regions to a given physiological or stressful stimulus. Thus, the described anatomy of the HNS and the brain OXT system provide the basis for the description of mainly coordinated, but also independent release of OXT into blood and within the brain in a brain region- and stimulus-dependent manner $[24,39,40]$.

\section{Synaptic versus non-synaptic OXT release}

Although controversial discussion still remains [41], the central release of OXT may occur in a synaptic or nonsynaptic fashion, probably, as a combination of presynaptic terminal, axonal en passant, dendritic, and somatic release. These different modes of release contribute to the enormous functional complexity of the brain OXT system. Although parvocellular OXT neurons projecting to the hindbrain most likely synapse onto target cells [27, 41], the nature of axonal contacts of magnocellular remains elusive despite electron microscopic reports showing the presence of large densecore vesicles containing OXT in synaptic terminals within the SON, ventromedial hypothalamus, lateral septum, amygdala and nucleus of the solitary tract [30, 42-46]. Further, in vivo evidence for extracellular $\mathrm{Ca}^{2+}$-dependent synaptic release of nonapeptides within the septum, SON and PVN exists demonstrating that depolarizing stimuli, or omission of $\mathrm{Ca}^{2+}$, can stimulate, or prevent, such local release [47-49]. In contrast, so far, large dense-core OXT vesicles have not been located in the active zones of pre-synapses in the few OXT synapses found in the SON $[45,50]$ and ventromedial hypothalamic nucleus [43]. Moreover, OXTR have not been identified in postsynaptic membranes. Together with electrophysiological evidence speaking against synaptic neurotransmission of 
nonapeptides [51], it is likely that microscopically visualized synapses [23, 30, 45] operate by classical neurotransmitters rather than OXT. Therefore, intracerebral release of OXT from magnocellular neurons should occur mainly non-synaptically, either from axonal collaterals en passant or axonal terminals within the forebrain and other limbic regions, as well as from dendrites and somata within the hypothalamic PVN and SON. Pow and Morris were the first to provide electron microscopic evidence for such dendritic release of OXT from magnocellular neurons within the SON [52], which does not contain parvocellular OXT cells.

When released non-synaptically, OXT molecules diffuse into the surrounding space and act as neuromodulator rather than classical neurotransmitter by binding to nearby OXTR in virtually all major forebrain brain regions [2, 24, 53, 54] (summarized in Fig. 2). Recent calculations on the effective OXT concentrations around the site of OXT release have revealed a radius of about 55-120 $\mu \mathrm{M}$ [55]; beyond this radius, OXT concentrations are not sufficient to activate local OXTR. This excludes the possibility that diffusion of OXT to neighboring or even further distant brain regions significantly contributes to its neuronal or behavioral actions.

Both parvo- and magnocellular OXT neurons co-express glutamate as a conventional neurotransmitter. However, the balance between expression of OXT and glutamate in the same neuron remains unclear. Although parallel elevation of the vesicular glutamate transporter vGlutT2 and of OXT mRNA levels has been reported in magnocellular OXT cell bodies after osmotic challenge [56], and the presence of vGluT2 immunosignal was detected in terminals of OXT neurons in the posterior lobe of the pituitary [57], to our knowledge only two functional studies tackled the question of axonal OXT and glutamate co-release [30, 34]. The first work [30] reported the presence of putative (asymmetric) glutamatergic synapses formed by axons of hypothalamic OXT neurons in the central nucleus of amygdala. To validate this finding functionally, the authors activated OXT axonal terminals in acute amygdala slices from rats subjected to fear conditioning and found a small glutamatemediated response of postsynaptic cells. Intriguingly, Hasan and colleagues showed activated glutamatergic over OXTergic transmission in rats, which previously experienced fear. This shift was further confirmed in vivo via evoking OXT and glutamate release demonstrating that the rapid onset of mobility in fear-conditioned rats remained even after the block of OXTRs by its selective antagonist. Thus, these two reports support the general notion that the coordinated release of a slow-acting neuropeptide neuromodulator and a fast-acting amino acid neurotransmitter is a mechanism essential for the modulation of cognitive, emotional and metabolic processes [58]. However, potentially simultaneous synaptic glutamate and non-synaptic OXT releases from the very same axon request further studies implementing highresolution imaging techniques.

\section{Stimulus-dependent release of OXT in distinct brain regions}

The dynamics of OXT release within distinct brain regions has been mainly studied using intracerebral microdialysis performed in rats, mice, sheep, and voles. In this context, both, commercially available concentric microdialysis probes [59] as well as self-constructed U-shaped microdialysis probes (for review see $[60,61]$ ) have been successfully employed in different laboratories. The latter consist of two parallel 23-g stainless steel cannulas with the microdialysis membrane originating, for example, from an artificial kidney (pores of $10-20 \mathrm{kDa})$ inserted into the ends of two cannulas and bended to the U-shaped form. Although brain microdialysis is an invasive approach, there is convincing experimental evidence that plasma OXT from intracerebral capillaries does not significantly contribute to the neuropeptide content quantified in microdialysates [1, 48, 49, 62]. For example, we had roughly estimated that OXT concentration in the extracellular fluid of the SON is about 100-1000-fold higher than that in plasma [63]. This is an important prerequisite allowing separate monitoring of central versus peripheral OXT release patterns in response to a given stimulus.

A major advantage of intracerebral microdialysis is the fact that it can be performed in conscious, freely behaving animals, which allows studying intracerebral OXT release not only in response to physiological stimuli, but also during ongoing behavioral observation. Thus, OXT release has been successfully monitored within various limbic target regions, including the rat and mouse dorsolateral and ventral septal areas [48, 64-66], the rat dorsal hippocampus [48, 67] and central amygdala [68], the nucleus accumbens of voles [69], the substantia nigra, olfactory bulb, bed nucleus of the stria terminalis and medial preoptic area of sheep [59, 70], and within the rat nucleus of the solitary tract [62, 71] (Fig. 2).

Electrical or optogenetic stimulation of the PVN was described to stimulate OXT release within the septum [48, 72], central amygdala [30], anterior olfactory cortex [73], and the nucleus of the solitary tract [71]. Further, somato-dendritic release of OXT within its nuclei of origin, i.e., within the hypothalamic SON and PVN, has also been extensively studied mainly in rats [49, 62, 74-76]. However, due to sensitivity limitations, it is presently impossible to exclusively measure release of OXT from the small population of parvocellular neurons within the PVN. Consequently, the results summarized below should 
reflect the intra-PVN release of the neuropeptide mainly from magnocellular cells, or a combination of both, magno- and parvocellular neurons.

\section{Stimuli triggering intracerebral OXT release}

Physiological, stressful, and pharmacological stimuli of intracerebral OXT release have been extensively studied and discussed (for review see [1, 40, 77-79]). So far, all reproductive stimuli, such as birth, suckling in the lactating animal, and mating in males and females, which were all shown to activate the secretion of OXT as a neurohormone into the blood stream, were also found to trigger OXT release within the brain in a region-dependent manner. Thus, in response to the reproductive stimuli mentioned above, increased OXT release has been shown in the PVN, SON, septum, dorsal hippocampus, bed nucleus of the stria terminalis, olfactory bulb, nucleus accumbens, and medial preoptic area [29, 48, 59, 75, 80-82] for review see [1, 24]. Also, various physiological [67, 83], physical and emotional $[49,77]$ stressors stimulate not only OXT secretion into blood, but also intracerebral release. Relevant emotional stimuli include forced swimming (PVN, SON, and amygdala) [50, 68, 84-86] and shaker stress (PVN) [87]. Also, OXT release is stimulated in male rats by exposure to social defeat by an aggressive male resident (SON, septum, but not PVN) [64, 88], and in virgin female rats by exposure to maternal defeat by an aggressive lactating female resident (PVN, but not amygdala or septum) [89]. The latter examples provide striking evidence for region-dependent release of OXT, which, moreover, occurs independent of peripheral OXT secretion. OXT release within the PVN and central amygdala has also been found during the display of aggressive behavior in lactating [89] and virgin female [90] rats (for review [91]). However, whether aggressive encounters are accompanied by release of OXT into the blood stream is currently unknown.

Such aversive and stressful stimuli are accompanied by an activation of the hypothalamic-pituitary-adrenal (HPA) axis, and multiple interactions between the OXT system and the HPA axis exist [92, 93]. For example, stress-induced plasma corticosterone seems to promote the simultaneous release of OXT within the PVN [84], whereas OXT is rather considered to exert an inhibitory tone on hypothalamic CRF expression [94] and on general HPA axis responsiveness [95] (for review see [96]). This becomes particularly visible in lactation, when high brain OXT levels were found to impact on the attenuated response of the HPA axis [97].

Even subtle, largely stress-free social stimuli, such as social investigation of an unknown conspecific, result in elevated electrical activity of OXT neurons $[98,99]$ and a measurable increase in OXT concentrations in the extracellular fluid, for example, within the lateral septum of male mice [66] and rats [65]. Specialized OXT pathways described above consisting of only a few neuronal connections are activated by social interactions and seem to be essential for overcoming social fear [33] and, consequently, for promoting naturally occurring social preference behavior or social memory $[65,100]$. Whether such mild social stimuli are also activating OXT secretion into blood is unknown; we hypothesize that such secretion may occur in low and, therefore, not detectable quantities.

Recent attempts to reveal the behavioral relevance of OXT neuronal circuitries and local OXT release have substantially benefitted from viral vector-based optogenetic [101] and chemogenetic [102] approaches, which enable the highly selective stimulation of endogenous OXT release. Optogenetic activation of OXT neurons has been repeatedly used to reveal behavioral or physiological effects of locally released OXT [30, 73, 103-105]. Knobloch et al. were the first to apply optogenetics for stimulation of magnocellular OXT neurons. In this study, the blue light stimulation of channelrhodopsin-2-expressing OXT axons within the lateral part of the central nucleus of amygdala decreased freezing responses in fear-conditioned rats [30] — an effect, which has recently been confirmed by the same group [34]. Later, Xiao et al. used blue light stimulation to facilitate OXT release from axons of parvocellular PVN OXT neurons within the ventral tegmental area and showed specific activation of local midbrain dopamine neurons. In contrast, within the substantia nigra, optic stimulation of local OXT release indicated an inhibitory effect on dopamine neurons, likely to be mediated by activation of OXTR-expressing GABA neurons [105].

However, so far, attempts to provide direct evidence for optogenetic induction of release of OXT, either within the brain or into the blood, is missing or failed. In our own first pilot experiment (unpublished), we optogenetically stimulated OXT release from axons in the central amygdala in analogy to a previous study [30], and used microdialysis to simultaneously monitor local OXT release. However, we were unable to detect any increase in OXT concentrations in microdialysates. Based on previous results that blue light stimulation of OXT axons in the amygdala induced activation of OXT-sensitive neurons and behavioral effects, the lack of a detectable rise in local OXT release may be explained by the limited sensitivity of microdialysis with a relative recovery of nonapeptides of only 2-3\% from the extracellular fluid [1, 106]. Moreover, although the available radioimmunoassays with a detection limit in the $0.1-1 \mathrm{pg}$ range are highly sensitive, at least $10^{10}$ molecules of OXT have to be present in the extracellular fluid for quantification. In contrast, the release of even one large dense-core vesicle containing $\sim 80.000$ OXT molecules may bind to OXTRs in surrounding neurons to change their 
electrical activity [55], resulting in the modification of local networks transmitted into behavior.

Another method of choice for highly selective manipulation of intracerebral OXT release is the DREADD (designer receptor exclusively activated by designer drug) technology, which requires the blood-brain barrier permeable DREADD ligand clozapine N-oxide (CNO) [33]. This chemogenetic method has the striking advantage that additional stereotaxic implantation of optic fibers necessary for optogenetic stimulation can be avoided. Viral vector-based expression of different classes of DREADDs, such as Gq- and Gi-coupled DREADDs, driven by the cell type-specific OXT promoter allows neuronal activation and inhibition, respectively. Thus, the activation of $\mathrm{Gq}$ DREADD- (hM3Dq) expressing OXT neurons by CNO resulted in elevated neuronal firing, intracellular $\mathrm{Ca}^{2+}$ levels and intra-PVN somato-dendritic and neurohypophysial release of OXT [102]. Moreover, chemogenetic activation of PVN OXT neurons increased the endocannabinoid anandamide content in the nucleus accumbens in an OXTR-dependent manner, indicating chemogenetically induced local OXT release [107]. In contrast to these gain-of-function studies, loss-of-function analyses are based on Gi-coupled DREADD (hM4Di) [23]. For example, selective CNO-induced inhibition of those hypothalamic OXT neurons expressing hM4Di and projecting to the lateral septum completely abolished social investigation and induced social fear in lactating mice [33].

Thus, opto- and chemogenetics alone or in combination are important tools to selectively manipulate local OXT release, thus allowing to reveal the detailed involvement of subpopulations of OXT neurons and their projections in behavioral and physiological functions. Although optogenetics allows very precise temporal resolution, the stimulation of OXT axons may potentially result in propagation of action potentials along their axonal collaterals, making the identification of precise structures underlying blue light- induced behavioral effects problematic [108]. To verify this issue, chemogenetics can be helpful as the DREADD ligand CNO can also be infused into the region of interest acting locally on DREADD-expressing OXT axonal terminals, thus preventing back-propagation of action potentials via axons and cell bodies [34].

In summary, OXT release monitored by intracerebral microdialysis reflects the dynamic activity of the brain OXT system. It can be characterized as strictly regionand stimulus-dependent, may occur simultaneously or at least coordinated with OXT secretion into blood, or may be independent of it [1, 24]. Indeed, differences in the temporal dynamics of peripheral and central release patterns and in the pharmacokinetics of OXT in the brain extracellular fluid versus blood compartment exist. Therefore, there is general agreement that blood OXT cannot be considered as an indicator of the activity of the brain OXT system [2, 109].

\section{Intraneuronal OXTR-mediated signaling}

It is truly amazing that the large variability of behavioral and physiological effects of OXT after its release within distinct brain regions is based on ligand binding to a single kind of OXTR expressed by neurons or glia cells in numerous hypothalamic, limbic, cortical, and brain stem regions (for summary see Table 1 in [1]). However, to this end the stimulus-dependent release of OXT has to be balanced with a fine-tuned regulation of local OXTR expression and binding. The many regulatory modes of OXTR expression include ligand availability [110, 111], epigenetic mechanisms, such as DNA methylation in the promoter of the Oxtr [112] and microRNAs [113], and estrogen-receptor $\alpha$ or $\beta$ activation [114-116] resulting in brain region-specific and temporal dynamic patterns of OXTR binding. Moreover, individual OXTR binding is dependent on the developmental or reproductive stage, and on exposure to acute or chronic stressors. Desensitization and internalization of the OXTR upon ligand binding further add to the regulatory complexity of this receptor. These adaptations, which have been extensively reviewed elsewhere [1, 117], provide the molecular basis underlying appropriate behavioral adaptations to age- and stimulusdependent social or emotional demands [118, 119]. Consequently, maladaptations in central OXTR binding, which have already been associated with social stress and social fear in rodents $[66,120,121]$, are likely to contribute to the etiology of psychopathologies [122].

Whereas the duration and intensity of neuronal actions are mainly determined by the concentration of OXT in the extracellular fluid, and by OXTR density and affinity, the quality of acute or long-term neuronal effects of OXT is mainly dependent on subsequent activation of intracellular signaling cascades [123, 124] (Fig. 3). As a G (guanine nucleotide-binding) protein-coupled receptor (GPCR), the OXTR interacts with heterotrimeric G-protein complexes $\left(G_{\alpha}, G_{\beta}\right.$, and $\left.G_{\gamma}\right)$ and can be linked to multiple signaling pathways depending on the specific G-protein complex involved (e.g., $G_{\alpha q}, G_{\alpha o}$, and $G_{\alpha i}$ ) (for review see $[1,117]$ ). For example, activation of the $G_{\alpha}$ proteins $G_{\alpha q}$ and $G_{\alpha 11}$, which are both expressed in the brain, stimulates phospholipase $\mathrm{C}$ resulting in the generation of inositol 1,4,5triphosphate (IP3) and 1,2-dicyaglycerol (DAG). Whereas IP3 mobilizes $\mathrm{Ca}^{2+}$ from intracellular stores, DAG activates protein kinase $\mathrm{C}(\mathrm{PKC})$ and, thus, phosphorylates a number of other downstream target proteins.

Another important intraneuronal signaling pathway activated by OXTR both via Gq/11 and Gi/o is the mitogen- 


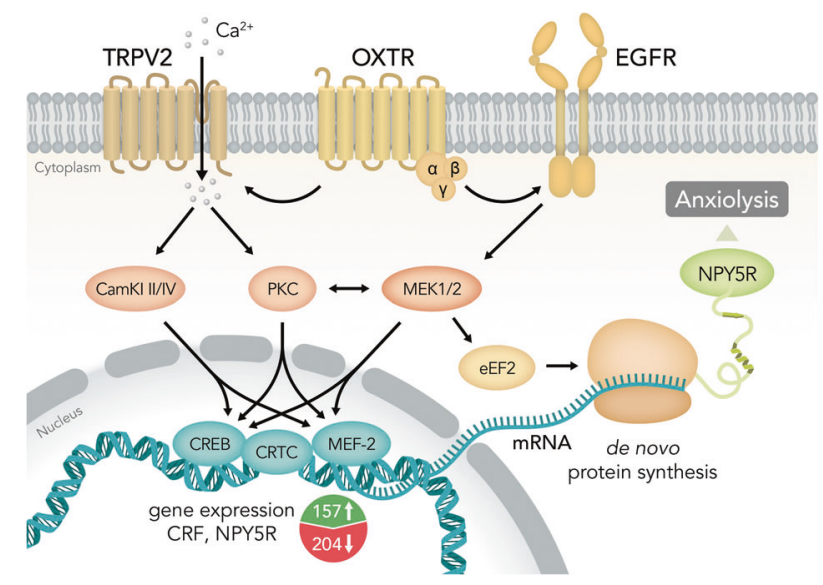

Fig. 3 Scheme of intraneuronal signaling cascades involved in OXT-induced anxiolysis in the hypothalamic paraventricular nucleus. Activation of the OXT receptor (OXTR) elevates - via the $\mathrm{G} \beta / \gamma$ protein subunit - extracellular $\mathrm{Ca}^{2+}$ influx via incorporation of TRPV2 $\mathrm{Ca}^{2+}$ channels into the cellular membrane and subsequent activation of $\mathrm{Ca}^{2+}$-dependent cascades (PKC, CaMKI, II, IV). OXTR activation via its G-protein $\alpha_{\mathrm{q}}$ subunit also leads to transactivation of EGFR and subsequent activation of the MAPK pathway via MEK1/2. The signaling cascades converge on downstream regulation of transcriptions factors, such as MEF2, CREB, and its cofactor CRTC3 and, consequently, modulate neuronal gene expression. Central infusion OXT resulted in 157 up- and 204 downregulated genes identified in rat PVN tissue punches (Affymetrix microarray [131] GEO dataset). Moreover, through activation of PKC and MEK1/2, OXT regulates eEF2 activity to promote protein de novo synthesis, e.g., synthesis of the NPY5R. $\mathrm{Ca}^{2+}$ calcium, TRPV2 transient receptor potential cation channels of vanilloid type 2, EGFR epidermal growth factor receptor, CaMK calcium/calmodulin-dependent kinase, PKC protein kinase $\mathrm{C}$, MAPK mitogen-activated protein kinase pathway, MEK mitogenactivated protein kinase kinase, CRTC cyclic AMP-regulated transcriptional coactivators, CREB cyclic AMP responsive element binding protein, MEF2 myocyte enhancer factor 2, EF2 eukaryotic elongation factor 2, NPY5R neuropeptide Y 5 receptor. Adapted with allowance from $[1,131]$.

activated protein kinase (MAPK) cascade. We have demonstrated that this pathway, which requires both, transactivation of the epidermal growth factor receptor (EGFR) [125] and the influx of extracellular $\mathrm{Ca}^{2+}$ through transient receptor potential vanilloid type 2 (TRPV2) channels [126], is essential for the anxiolytic effect of OXT in the PVN of male and female rats [125-127]. Moreover, the hippocampal MEK1/2-MAPK cascade has also been associated with OXT-regulated spatial memory formation in lactating animals, which was shown to be CREB-dependent [128]. In fact, MAPK activation by MEK1/2 finally leads to the stimulation of the transcription factor CREB and subsequent regulation of its cofactor CRTC (TORC) in the nucleus and gene expression (Fig. 3) [94, 129-131]. After central infusion of OXT we identified 157 upregulated and 204 downregulated genes within the PVN. Among the upregulated genes was the neuropeptide $\mathrm{Y}$ receptor 5 (NPY5R) [131] (Fig. 3), which activity is sufficient for anxiolysis in general and necessary for the anxiolytic effect of OXT in particular. Interestingly, OXTR-activated de novo protein synthesis further involves the eukaryotic elongation factor eEF2 [117], which was stimulated by OXT in a PKC-dependent manner within the PVN [131] (Fig. 3).

The listed intraneuronal pathways linking acute OXTR activation to cytoplasmic or nuclear targets are essential to induce a neuron-specific response ultimately resulting in behavioral or physiological responses. These pathways identified so far in hypothalamic or hippocampal neurons have mainly been associated with OXT-induced anxiolysis, memory formation and stress-related behaviors. The detailed intraneuronal responses to OXT in any other behavioral context are far from being understood. Neuronspecific OXTR-coupled pathways, which are likely to depend on the predominant quality of expressed OXTRcoupled G-proteins (e.g., $G_{q}$ or $G_{i}$ ), the neuron-specific density of OXTR expression, and the region-dependent types of neurons expressing the OXTR may contribute to the variability and specificity of neuronal responses resulting in multiple, sometimes even opposing behavioral effects of the neuropeptide. These and other factors, such as the duration of OXTR activation (acute versus chronic), or differential modulation of local regional circuits via acting on OXTR-expressing cells integrated into the local neuronal ensembles, may be responsible for the phenomenon that a single molecule binding to a single type of GPCR can induce an enormous variability of effects in the brain.

Remarkably, the comparative anatomy of OXTR distribution revealed strict regional differences between the rodent and primate brain. Whereas, in rodents, olfactionrelated brain regions are rich of OXTRs, in primates OXTRs are abundantly expressed in visual brain regions, such as the superior colliculus, pulvinar, and primary visual cortex [132]. This species-dependent OXTR distribution is not surprising as OXT affects distinct sensory modalities (e.g., olfaction in rodents and visual cues in humans), orchestrating speciesdependent strategies of social communications [133]. Although a recent study explored the distribution of OXTR mRNA in the human brain [134], the intracellular OXTR signaling in primate neurons remains enigmatic and, hence, requires the expansion of human pluripotent stem cell technologies for generation of human OXT [135] and OXTR neurons obtained from healthy donors as well as from patients afflicted with socio-emotional pathologies.

\section{Translational perspectives}

Looking back at 700 Mio years of evolution, it is remarkable that in nematodes (C. Elegans), 5\% (!) among all neurons express OXT-like peptides [136], while in the human brain this number corresponds to about $0.00006 \%(\sim 50.000$ 
OXT-ergic cells) of total number of neurons $\left(\sim 86 \times 10^{12}\right.$ cells $)$ [35]. In the light of these numbers, it is unbiasedly impressive that IN application of OXT in humans modulates a plethora of social and emotional behaviors, among other physiological effects $[15,1,137]$. In human studies, IN OXT is mostly administered to healthy (predominantly male) volunteers or to patients suffering from deficits in socio-emotional behavior, as seen in autism spectrum disorder, borderline personality disorder, schizophrenia, or social phobia. Subsequently, OXT versus placebo treatment effects are assessed on specific behavioral tasks or on brain activity patterns in either a within-subject or a group design, which have been extensively reviewed elsewhere $[1,15,137-139]$. Thus, substantial effects of IN OXT were described on social cognition [138, 140-142], fear [143, 144], empathy [145, 146], trust [147], and even xenophobia [148, 149] often accompanied by altered neuronal activity [150].

Although the passage of IN OXT via the blood-brain barrier is still under debate [109] numerous reports in both rodents [151, 152] monkeys [153] and humans [154, 155] indicate the delivery of IN OXT into the brain in sufficient amounts. Recently, deuterated OXT has been detected in the CSF [153] and various brain tissues, including orbitofrontal cortex, thalamus, and striatum of macaques [156]. In line, a recent study of Paloyelis et al. addressed an important question regarding intracerebral effects of IN OXT and showed changes in regional blood flow in the human brain [157]. They used arterial spin labeling magnetic resonance imaging to quantify the resting-state blood flow in a defined tissue volume and time period $(\mathrm{ml}$ blood flow per $\mathrm{g}$ tissue per min) and found an OXT-induced elevation in regional blood flow in four brain regions belonging to the social brain network, i.e., in regional clusters comprising the amygdala, striatum, hippocampus, anterior and middle cingulate cortex, inferior frontal gyrus, and insular cortex.

These and the described promising behavioral effects of OXT have generated an enormous interest in IN OXT in patients, psychiatrists and psychologists, and in the general public, alike. They provided the perspective to use IN OXT as a treatment option for psychopathologies associated with socio-emotional dysfunctions, such as autism spectrum disorders, anxiety disorders, social phobia, and schizophrenia [15, 137, 139]. However, a substantial individual variation in the efficacy of IN OXT effects on socioemotional behaviors and brain function is likely depending on gender, childhood experiences, attachment style, personality, OXTR polymorphisms, and social support. This implies the substantial need for a precision medicine approach to optimize targeted treatments with OXT [137].

Moreover, a controversial discussion is still addressing questions regarding the reliability and validity of human OXT studies [158] due to small sample sizes and low statistical power, and lack of detailed dose-response studies. Also, the details regarding the mechanisms and routes of uptake of IN OXT in substantial amounts reaching those brain regions involved in the respective behaviors are still under debate $[1,109,151,158,159]$. Possible routes of IN OXT penetrance include uptake into the olfactory and trigeminal nerves connecting to the olfactory bulb and other brain regions, uptake via the nasal vascular mucosa with high capillary density, uptake into regions lacking a blood-brain barrier, i.e., the circumventricular organs, and limited transport across the blood-brain barrier. Especially the extremely high amounts of OXT generally applied IN may allow the latter route of transport, as only an uptake of $0.005 \%$ of applied OXT can be achieved [1]. Interestingly, the role of the seven circumventricular organs lacking the blood-brain barrier, but expressing OXTR (see Table 1 in [1]), and their neuronal connections to various brain regions have not been investigated as targets for circulating OXT yet. Moreover, OXT actions at peripheral OXTR abundantly expressed in the heart, skin, and autonomic nervous system including gastric vagal nerves (see Table 2 in [1]) are likely to mediate peripheral OXT signals after IN OXT to the brain.

So far, neither reliable side effects nor adverse consequences have been reported in males or females, adults or children after acute IN application of OXT (versus placebo) at doses between 18 and 40 IU [160, 161]. However, a different picture may emerge after chronically applied OXT. Despite the fact that more detailed investigations on the effects of chronic OXT treatment in large quantities are required, the available studies performed in mice and voles describe adverse behavioral effects accompanied by changes in intracerebral OXTR expression and binding $[110,111,162]$. Also, alterations in the fine-tuning of OXTR-mediated intraneuronal signaling and interregional connectivity have to be considered $[1,163]$. Such studies may have enormous implications for the use of IN OXT as long-term treatment for psychopathologies. For example, given the modulatory cardiovascular effects of OXT [164, 165], people with heart and cardiovascular conditions may be more vulnerable to the effects of OXT [161].

Given the central role of OXT for higher brain functions, it is not surprising that variations in the Oxtr gene, i.e., single nucleotide polymorphisms (SNPs), have been associated with individual differences in human behavior, physiology, and brain anatomy $[15,166,167]$. Thus, SNPs in the Oxtr have been associated with the feeling of loneliness [168], emotional withdrawal [169], emotion and sociality dysregulation [170], distress [171], decreased empathy [172], and decreased maternal sensitivity [173], but also with disorders such as autism [167, 174] (for review see [1]). However, limited evidence exists regarding the structural and/or functional consequences of SNPs in the Oxtr gene. To this end, it seems surprising that only very recently, the crystal structure of the human OXTR has been 
solved, although in an inactive form as complex with retosiban, a non-peptide antagonist [175].

Another direction of OXT research in humans stems from the modulation of activity of endogenous OXT system to amend emotional or social deficits. This can be achieved either physiologically $[84,176,177]$ or pharmacologically $[178,179]$. For example, physical exercise such as running or swimming, and close social interactions with, but even without direct physical contact were shown to significantly stimulate the OXT system reflected by increased neuronal activity, OXT synthesis, its intracerebral release or secretion into the blood stream [49, 66, 70, 80-82, 84, 86, 152, 153].

Alternatively, the development of more sophisticated delivery approaches may contribute to a more specific and efficient increase in OXT availability in the ECF of human patients identified with OXT system deficits. For example, Prescott et al. were able to subcutaneously implant a microchip into a dog over a period of 6 months, and this microchip released the neuropeptide leuprolide (the analog of gonadotropin releasing hormone) from 100 different, individually addressable reservoirs [180]. Future advances in this field might soon allow for substance release from peripheral tissue implants, which stimulate endogenous OXT release via activation of peripheral receptors [181183]. Whether intra-brain implants to locally release drugs in the respective brain regions will ever become a serious treatment option remains to be shown. So far, IN application of OXT in combination with professional psychotherapy proved to be a promising approach for the treatment of patients suffering from PTSD, as there are no other effective drugs available so far [184-186]. However, the cellular and molecular mechanisms of OXT actions after IN application have to be addressed in more detail to exclude subtle side effects, for example, after chronic OXT treatment.

A promising strategy in this context could be to encourage translational studies and the formation of tandem studies, i.e., animal and human researchers work in parallel on a given subject (e.g., psychopathology, activity of neural circuits, and stimulus condition) so that promising findings can immediately be tested for the relevance in the respective other species. Given the ever-growing body of available techniques and resources, as well as advances in the field of translational research [187, 188], we should be optimistic that the quality of results from such studies will constantly improve over the next years.

\section{The OXT system in times of the COVID-19 crisis}

There is profound evidence for an important role of the brain OXT system including neuronal circuits and receptormediated downstream signaling in regulating socio-emotional behavior and stress responses under healthy physiological conditions. Not only physical exercise, but especially close social interactions associated with relevant physiological or sensory stimuli activate central OXT expression and release with beneficial mental health effects. In contrast, dysregulation of any aspect of the complex neuropeptide system driven by acute environmental, genetic, or epigenetic factors, is likely to contribute to psychopathologies associated with stress-induced socio-emotional dysfunctions. The present disastrous situation after the coronavirus outbreak known as COVID-19 is characterized by country-wide regulations with the aim to combat the spread of the severe acute respiratory syndrome coronavirus 2 (SARS-CoV-2). Drastic restrictions for the general public include curfew, home quarantine or home office, and to generally keep physical distance to any other person outside the household in many countries. All these regulations have in common a dramatic social isolation, and lack of face-to-face and physical interactions with relatives, friends, or colleagues. As close social interactions are an important mental health-protecting factor, a social isolationinduced increase in fear and anxiety, depression, and feelings of stress can be predicted [189]. In support, a general population survey [190] revealed widespread concerns about the consequences of the corona crisis associated with social distancing on mental well-being. Interestingly, the prospect of becoming physically unwell with COVID-19 ranked lower than issues related to the social and psychological response to the pandemic [190].

For three reasons, the OXT system should increasingly come into focus of the scientific discussion regarding the causes and consequences of corona-induced impairments of mental health. First, physical distancing and lack of direct social interactions due to social isolation have adverse effects on the activity of the OXT system: social isolation results in lower density of neuronal branching (Neumann and Grinevich, unpublished), and reduced neuropeptide synthesis, and prevents socially stimulated central OXT release [66, 191, 192]. Second, social support is an important factor for our mental and physical well-being and for the recovery from any disease [193, 194], and these effects are at least partly mediated by the OXT system [195-198] (for review see [39]). Finally, due to the pro-social and anti-stress effects of the brain OXT system, IN application of the synthetic peptide or efficient activation of the endogenous OXT are potential options to prevent or reverse social isolation-induced impairment in mental well-being and the development of serious psychopathologies, associated with such a dramatic crisis affecting our social lives.

Acknowledgements This work was supported by the German Research Foundation (DFG) grants GR 3619/7-1, GR 3619/8-1, and GR 3619/13-1, Collaborative Research Center SFB 1158, and Fritz Thyssen Research Foundation (Ref. 10.19.1.015MN) to VG, and by DFG grants NE 465/27, NE 465/31, and NE 465/34, the DFG 
Graduate Research School (GRK) 2174, the Federal Ministry of Education and Research (BMBF; OptiMD) and the EU (FemNat-CD) to IDN. We thank Dr. Ferdinand Althammer for providing the image for Fig. 1, Dr. Benjamin Jurek for input to Fig. 3, and Thomas Splettstoesser (www.scistyle.com) for his help with the preparation of Figs. 2 and 3.

\section{Compliance with ethical standards}

Conflict of interest The authors declare that they have no conflict of interest.

Publisher's note Springer Nature remains neutral with regard to jurisdictional claims in published maps and institutional affiliations.

\section{References}

1. Jurek B, Neumann ID. The oxytocin receptor: from intracellular signaling to behavior. Physiol Rev. 2018;98:1805-908.

2. Neumann ID, Landgraf R. Balance of brain oxytocin and vasopressin: implications for anxiety, depression, and social behaviors. Trends Neurosci. 2012;35:649-59.

3. Neumann I, Landgraf R, Bauce L, Pittman QJ. Osmotic responsiveness and cross talk involving oxytocin, but not vasopressin or amino acids, between the supraoptic nuclei in virgin and lactating rats. J Neurosci. 1995;15:3408-17.

4. Landgraf R, Gerstberger R, Montkowski A, Probst JC, Wotjak CT, Holsboer F, et al. V1 vasopressin receptor antisense oligodeoxynucleotide into septum reduces vasopressin binding, social discrimination abilities, and anxiety-related behavior in rats. J Neurosci. 1995;15:4250-8.

5. Frank E, Landgraf R. The vasopressin system-from antidiuresis to psychopathology. Eur J Pharmacol. 2008;583:226-42.

6. Deussing JM, Chen A. The corticotropin-releasing factor family: physiology of the stress response. Physiol Rev. 2018;98: 2225-86.

7. Wu G, Feder A, Wegener G, Bailey C, Saxena S, Charney D, et al. Central functions of neuropeptide $\mathrm{Y}$ in mood and anxiety disorders. Expert Opin Ther Targets. 2011;15:1317-31.

8. Slattery DA, Naik RR, Grund T, Yen YC, Sartori SB, Fuchsl A, et al. Selective breeding for high anxiety introduces a synonymous SNP that increases neuropeptide $S$ receptor activity. J Neurosci. 2015;35:4599-613.

9. Meis S, Bergado-Acosta JR, Yanagawa Y, Obata K, Stork O, Munsch T. Identification of a neuropeptide $S$ responsive circuitry shaping amygdala activity via the endopiriform nucleus. PLoS ONE. 2008;3:e2695.

10. Lukas M, Neumann ID. Nasal application of neuropeptide S reduces anxiety and prolongs memory in rats: social versus nonsocial effects. Neuropharmacology. 2012;62:398-405.

11. Shioda S, Gozes I. VIP and PACAP: novel approaches to brain functions and neuroprotection. Curr Pharm Des. 2011;17:961.

12. Kissileff HR, Gordon RJ, Thornton JC, Laferrere B, Albu J, PiSunyer $\mathrm{X}$, et al. Combined effects of cholecystokinin- 8 and gastric distension on food intake in humans. Am J Physiol Regul Integr Comp Physiol. 2019;317:R39-R48.

13. Donaldson ZR, Young LJ. Oxytocin, vasopressin, and the neurogenetics of sociality. Science. 2008;322:900-4.

14. MacDonald K, Feifel D. Oxytocin's role in anxiety: a critical appraisal. Brain Res. 2014;1580:22-56.

15. Meyer-Lindenberg A, Domes G, Kirsch P, Heinrichs M. Oxytocin and vasopressin in the human brain: social neuropeptides for translational medicine. Nat Rev Neurosci. 2011;12:524-38.
16. Grimmelikhuijzen CJ, Hauser F. Mini-review: the evolution of neuropeptide signaling. Regul Pept. 2012;177:S6-9.

17. Grinevich V, Knobloch-Bollmann HS, Eliava M, Busnelli M, Chini B. Assembling the puzzle: pathways of oxytocin signaling in the brain. Biol Psychiatry. 2016;79:155-64.

18. Armstrong WE. Hypothalamic supraoptic and paraventricular nuclei. In: The rat nervous system. Chapter 15, 3rd ed. Academic Press; 2004. p. 369-88.

19. Knobloch HS, Grinevich V. Evolution of oxytocin pathways in the brain of vertebrates. Front Behav Neurosci. 2014;8:31.

20. Burbach JP, Luckman SM, Murphy D, Gainer H. Gene regulation in the magnocellular hypothalamo-neurohypophysial system. Physiol Rev. 2001;81:1197-267.

21. Armstrong WE. Morphological and electrophysiological classification of hypothalamic supraoptic neurons. Prog Neurobiol. 1995;47:291-339.

22. Swanson LW, Sawchenko PE, Wiegand SJ, Price JL. Separate neurons in the paraventricular nucleus project to the median eminence and to the medulla or spinal cord. Brain Res. 1980; 198:190-5.

23. Eliava M, Melchior M, Knobloch-Bollmann HS, Wahis J, da Silva Gouveia M, Tang Y, et al. A new population of parvocellular oxytocin neurons controlling magnocellular neuron activity and inflammatory pain processing. Neuron. 2016;89:1291-1304.

24. Landgraf R, Neumann ID. Vasopressin and oxytocin release within the brain: a dynamic concept of multiple and variable modes of neuropeptide communication. Front Neuroendocrinol. 2004;25:150-76.

25. Ludwig M, Leng G. Dendritic peptide release and peptidedependent behaviours. Nat Rev Neurosci. 2006;7:126-36.

26. Alstein M, Whitnall MH, House S, Key S, Gainer H. An immunochemical analysis of oxytocin and vasopressin prohormone processing in vivo. Peptides. 1988;9:87-105.

27. Swanson LW, Sawchenko PE. Hypothalamic integration: organization of the paraventricular and supraoptic nuclei. Annu Rev Neurosci. 1983;6:269-324.

28. Buijs RM, De Vries GJ, Van Leeuwen FW, Swaab DF. Vasopressin and oxytocin: distribution and putative functions in the brain. Prog Brain Res. 1983;60:115-22.

29. Ross HE, Cole CD, Smith Y, Neumann ID, Landgraf R, Murphy $\mathrm{AZ}$, et al. Characterization of the oxytocin system regulating affiliative behavior in female prairie voles. Neuroscience. 2009; 162:892-903.

30. Knobloch HS, Charlet A, Hoffmann LC, Eliava M, Khrulev S, Cetin AH, et al. Evoked axonal oxytocin release in the central amygdala attenuates fear response. Neuron. 2012;73:553-66.

31. Dolen G, Darvishzadeh A, Huang KW, Malenka RC. Social reward requires coordinated activity of nucleus accumbens oxytocin and serotonin. Nature. 2013;501:179-84.

32. Sofroniew MV. Morphology of vasopressin and oxytocin neurones and their central and vascular projections. Prog Brain Res. 1983;60:101-14.

33. Menon R, Grund T, Zoicas I, Althammer F, Fiedler D, Biermeier V, et al. Oxytocin Signaling in the Lateral Septum Prevents Social Fear during Lactation. Curr Biol. 2018;28:1066-78 e1066.

34. Hasan MT, Althammer F, Silva da Gouveia M, Goyon S, Eliava $\mathrm{M}$, Lefevre A, et al. A fear memory engram and its plasticity in the hypothalamic oxytocin system. Neuron. 2019;103:133-146.e8.

35. Althammer F, Jirikowski G, Grinevich V. The oxytocin system of mice and men-Similarities and discrepancies of oxytocinergic modulation in rodents and primates. Peptides. 2018;109:1-8.

36. Althammer F, Grinevich V. Diversity of oxytocin neurons: beyond magno- and parvocellular cell types? J Neuroendocrinol. 2017. https://doi.org/10.1111/jne.12549.

37. Romanov RA, Zeisel A, Bakker J, Girach F, Hellysaz A, Tomer $\mathrm{R}$, et al. Molecular interrogation of hypothalamic organization 
reveals distinct dopamine neuronal subtypes. Nat Neurosci. 2017;20:176-88.

38. Hung LW, Neuner S, Polepalli JS, Beier KT, Wright M, Walsh $\mathrm{JJ}$, et al. Gating of social reward by oxytocin in the ventral tegmental area. Science. 2017;357:1406-11.

39. Neumann ID. The advantage of social living: brain neuropeptides mediate the beneficial consequences of sex and motherhood. Front Neuroendocrinol. 2009;30:483-96.

40. Neumann ID. Stimuli and consequences of dendritic release of oxytocin within the brain. Biochem Soc Trans. 2007;35:1252-7.

41. Buijs RM. Vasopressin and oxytocin-their role in neurotransmission. Pharmacol Ther. 1983;22:127-41.

42. Buijs RM, Swaab DF. Immuno-electron microscopical demonstration of vasopressin and oxytocin synapses in the limbic system of the rat. Cell Tissue Res. 1979;204:355-65.

43. Griffin GD, Ferri-Kolwicz SL, Reyes BA, Van Bockstaele EJ, Flanagan-Cato LM. Ovarian hormone-induced reorganization of oxytocin-labeled dendrites and synapses lateral to the hypothalamic ventromedial nucleus in female rats. J Comp Neurol. 2010;518:4531-45.

44. Peters JH, McDougall SJ, Kellett DO, Jordan D, Llewellyn-Smith IJ, Andresen MC. Oxytocin enhances cranial visceral afferent synaptic transmission to the solitary tract nucleus. J Neurosci. 2008;28:11731-40.

45. Theodosis DT. Oxytocin-immunoreactive terminals synapse on oxytocin neurones in the supraoptic nucleus. Nature. 1985; 313:682-4.

46. Voorn P, Buijs RM. An immuno-electronmicroscopical study comparing vasopressin, oxytocin, substance $\mathrm{P}$ and enkephalin containing nerve terminals in the nucleus of the solitary tract of the rat. Brain Res. 1983;270:169-73.

47. Buijs RM, Van Heerikhuize JJ. Vasopressin and oxytocin release in the brain-a synaptic event. Brain Res. 1982;252:71-76.

48. Neumann I, Landgraf R. Septal and hippocampal release of oxytocin, but not vasopressin, in the conscious lactating rat during suckling. J Neuroendocrinol. 1989;1:305-8.

49. Neumann I, Russell JA, Landgraf R. Oxytocin and vasopressin release within the supraoptic and paraventricular nuclei of pregnant, parturient and lactating rats: a microdialysis study. Neuroscience. 1993;53:65-75.

50. Wotjak CT, Kubota M, Liebsch G, Montkowski A, Holsboer F, Neumann I, et al. Release of vasopressin within the rat paraventricular nucleus in response to emotional stress: a novel mechanism of regulating adrenocorticotropic hormone secretion? J Neurosci. 1996;16:7725-32.

51. Son SJ, Filosa JA, Potapenko ES, Biancardi VC, Zheng H, Patel $\mathrm{KP}$, et al. Dendritic peptide release mediates interpopulation crosstalk between neurosecretory and preautonomic networks. Neuron. 2013;78:1036-49.

52. Morris JF, Pow DV. Widespread release of peptides in the central nervous system: quantitation of tannic acid-captured exocytoses. Anat Rec. 1991;231:437-45.

53. Leng G, Ludwig M. Neurotransmitters and peptides: whispered secrets and public announcements. J Physiol. 2008;586:5625-32.

54. Mitre M, Marlin BJ, Schiavo JK, Morina E, Norden SE, Hackett TA, et al. A distributed network for social cognition enriched for oxytocin receptors. J Neurosci. 2016;36:2517-35.

55. Chini B, Verhage M, Grinevich V. The action radius of oxytocin release in the mammalian CNS: from single vesicles to behavior. Trends Pharmacol Sci. 2017;1463:10.

56. Kawasaki A, Shutoh F, Nogami H, Hisano S. VGLUT2 expression is up-regulated in neurohypophysial vasopressin neurons of the rat after osmotic stimulation. Neurosci Res. 2006;56:124-7.

57. Hrabovszky E, Deli L, Turi GF, Kallo I, Liposits Z. Glutamatergic innervation of the hypothalamic median eminence and posterior pituitary of the rat. Neuroscience. 2007;144:1383-92.
58. van den Pol AN. Neuropeptide transmission in brain circuits. Neuron. 2012;76:98-115.

59. Kendrick KM, Keverne EB, Hinton MR, Goode JA. Oxytocin, amino acid and monoamine release in the region of the medial preoptic area and bed nucleus of the stria terminalis of the sheep during parturition and suckling. Brain Res. 1992;569:199-209.

60. Wotjak CT, Landgraf R, Engelmann M. Listening to neuropeptides by microdialysis: echoes and new sounds? Pharm Biochem Behav. 2008;90:125-34.

61. Neumann ID, Landgraf R. Tracking oxytocin functions in the rodent brain during the last 30 years: From push-pull perfusion to chemogenetic silencing. J Neuroendocrinol. 2019;31:e12695.

62. Russell JA, Neumann I, Landgraf R. Oxytocin and vasopressin release in discrete brain areas after naloxone in morphine-tolerant and -dependent anesthetized rats: push-pull perfusion study. J Neurosci. 1992;12:1024-32.

63. Landgraf R, Neumann I, Russell JA, Pittman QJ. Push-pull perfusion and microdialysis studies of central oxytocin and vasopressin release in freely moving rats during pregnancy, parturition, and lactation. Ann N Y Acad Sci. 1992;652:326-39.

64. Ebner K, Wotjak CT, Landgraf R, Engelmann M. A single social defeat experience selectively stimulates the release of oxytocin, but not vasopressin, within the septal brain area of male rats. Brain Res. 2000;872:87-92.

65. Lukas M, Toth I, Veenema AH, Neumann ID. Oxytocin mediates rodent social memory within the lateral septum and the medial amygdala depending on the relevance of the social stimulus: Male juvenile versus female adult conspecifics. Psychoneuroendocrinology. 2013;38:916-26.

66. Zoicas I, Slattery DA, Neumann ID. Brain oxytocin in social fear conditioning and its extinction: involvement of the lateral septum. Neuropsychopharmacology. 2014;39:3027-35.

67. Landgraf R, Neumann I, Schwarzberg H. Central and peripheral release of vasopressin and oxytocin in the conscious rat after osmotic stimulation. Brain Res. 1988;457:219-25.

68. Ebner K, Bosch OJ, Kromer SA, Singewald N, Neumann ID. Release of oxytocin in the rat central amygdala modulates stresscoping behavior and the release of excitatory amino acids. Neuropsychopharmacology. 2005;30:223-30.

69. Bosch OJ, Dabrowska J, Modi ME, Johnson ZV, Keebaugh AC, Barrett CE, et al. Oxytocin in the nucleus accumbens shell reverses CRFR2-evoked passive stress-coping after partner loss in monogamous male prairie voles. Psychoneuroendocrinology. 2016;64:66-78.

70. Kendrick KM, Keverne EB, Chapman C, Baldwin BA. Intracranial dialysis measurement of oxytocin, monoamine and uric acid release from the olfactory bulb and substantia nigra of sheep during parturition, suckling, separation from lambs and eating. Brain Res. 1988;439:1-10.

71. Landgraf R, Malkinson T, Horn T, Veale WL, Lederis K, Pittman QJ. Release of vasopressin and oxytocin by paraventricular stimulation in rats. Am J Physiol. 1990;258:R155-159.

72. Neumann I, Schwarzberg H, Landgraf R. Measurement of septal release of vasopressin and oxytocin by the push-pull technique following electrical stimulation of the paraventricular nucleus of rats. Brain Res. 1988;462:181-4.

73. Oettl LL, Ravi N, Schneider M, Scheller MF, Schneider P, Mitre $\mathrm{M}$, et al. Oxytocin enhances social recognition by modulating cortical control of early olfactory processing. Neuron. 2016;90: 609-21.

74. Hattori T, Sundberg DK, Morris M. Central and systemic oxytocin release: a study of the paraventricular nucleus by in vivo microdialysis. Brain Res Bull. 1992;28:257-63.

75. Moos F, Poulain DA, Rodriguez F, Guerne Y, Vincent JD, Richard P. Release of oxytocin within the supraoptic nucleus during the milk ejection reflex in rats. Exp Brain Res. 1989;76:593-602. 
76. Ludwig M, Callahan MF, Morris M. Effects of tetrodotoxin on osmotically stimulated central and peripheral vasopressin and oxytocin release. Neuroendocrinology. 1995;62:619-27.

77. Engelmann M, Landgraf R, Wotjak CT. The hypothalamicneurohypophysial system regulates the hypothalamic-pituitaryadrenal axis under stress: an old concept revisited. Front Neuroendocrinol. 2004;25:132-49.

78. Neumann ID. Brain oxytocin: a key regulator of emotional and social behaviours in both females and males. J Neuroendocrinol. 2008;20:858-65.

79. Veenema AH, Neumann ID. Central vasopressin and oxytocin release: regulation of complex social behaviours. Prog Brain Res. 2008;170:261-76.

80. Neumann I, Ludwig M, Engelmann M, Pittman QJ, Landgraf R. Simultaneous microdialysis in blood and brain: oxytocin and vasopressin release in response to central and peripheral osmotic stimulation and suckling in the rat. Neuroendocrinology. 1993; 58:637-45.

81. Nyuyki KD, Waldherr M, Baeuml S, Neumann ID. Yes, I am ready now: differential effects of paced versus unpaced mating on anxiety and central oxytocin release in female rats. PLoS ONE. 2011;6:e23599.

82. Waldherr M, Neumann ID. Centrally released oxytocin mediates mating-induced anxiolysis in male rats. Proc Natl Acad Sci USA. 2007;104:16681-4.

83. Ludwig M, Callahan MF, Neumann I, Landgraf R, Morris M. Systemic osmotic stimulation increases vasopressin and oxytocin release within the supraoptic nucleus. J Neuroendocrinol. 1994; 6:369-73.

84. Torner L, Plotsky PM, Neumann ID, de Jong TR. Forced swimming-induced oxytocin release into blood and brain: effects of adrenalectomy and corticosterone treatment. Psychoneuroendocrinology. 2016;77:165-74.

85. Wigger A, Neumann ID. Endogenous opioid regulation of stressinduced oxytocin release within the hypothalamic paraventricular nucleus is reversed in late pregnancy: a microdialysis study. Neuroscience. 2002;112:121-9.

86. Wotjak CT, Ganster J, Kohl G, Holsboer F, Landgraf R, Engelmann M. Dissociated central and peripheral release of vasopressin, but not oxytocin, in response to repeated swim stress: new insights into the secretory capacities of peptidergic neurons. Neuroscience. 1998;85:1209-22.

87. Nishioka T, Anselmo-Franci JA, Li P, Callahan MF, Morris M. Stress increases oxytocin release within the hypothalamic paraventricular nucleus. Brain Res. 1998;781:57-61.

88. Engelmann M, Ebner K, Landgraf R, Holsboer F, Wotjak CT. Emotional stress triggers intrahypothalamic but not peripheral release of oxytocin in male rats. J Neuroendocrinol. 1999;11: 867-72.

89. Bosch OJ, Kromer SA, Brunton PJ, Neumann ID. Release of oxytocin in the hypothalamic paraventricular nucleus, but not central amygdala or lateral septum in lactating residents and virgin intruders during maternal defence. Neuroscience. 2004;124:439-48.

90. Oliveira VEM, Neumann ID, de Jong TR. Post-weaning social isolation exacerbates aggression in both sexes and affects the vasopressin and oxytocin system in a sex-specific manner. Neuropharmacology. 2019;156:107504.

91. de Jong TR, Neumann ID. Oxytocin and aggression. Curr Top Behav Neurosci. 2018;35:175-92.

92. Neumann ID, Wigger A, Torner L, Holsboer F, Landgraf R. Brain oxytocin inhibits basal and stress-induced activity of the hypothalamo-pituitary-adrenal axis in male and female rats: partial action within the paraventricular nucleus. J Neuroendocrinol. 2000;12:235-43.

93. Windle RJ, Kershaw YM, Shanks N, Wood SA, Lightman SL, Ingram $\mathrm{CD}$. Oxytocin attenuates stress-induced c-fos mRNA expression in specific forebrain regions associated with modulation of hypothalamo-pituitary-adrenal activity. J Neurosci. 2004;24:2974-82.

94. Jurek B, Slattery DA, Hiraoka Y, Liu Y, Nishimori K, Aguilera $\mathrm{G}$, et al. Oxytocin regulates stress-induced Crf gene transcription through CREB-regulated transcription coactivator 3. J Neurosci. 2015;35:12248-60.

95. Neumann ID, Kromer SA, Toschi N, Ebner K. Brain oxytocin inhibits the (re)activity of the hypothalamo-pituitary-adrenal axis in male rats: involvement of hypothalamic and limbic brain regions. Regul Pept. 2000;96:31-38.

96. Neumann ID. Involvement of the brain oxytocin system in stress coping: interactions with the hypothalamo-pituitary-adrenal axis. Prog Brain Res. 2002;139:147-62.

97. Neumann ID, Torner L, Wigger A. Brain oxytocin: differential inhibition of neuroendocrine stress responses and anxiety-related behaviour in virgin, pregnant and lactating rats. Neuroscience. 2000;95:567-75.

98. Resendez SL, Namboodiri VMK, Otis JM, Eckman LEH, Rodriguez-Romaguera J, Ung RL, et al. Social stimuli induce activation of oxytocin neurons within the paraventricular nucleus of the hypothalamus to promote social behavior in male mice. $\mathrm{J}$ Neurosci. 2020;40:2282-95.

99. Tang Y, Benusiglio D, Lefevre A, Hilfiger L, Althammer F, Bludau A, et al. Social touch promotes inter-female communication via oxytocin parvocellular neurons. Nat Neurosci. 2020 (in press).

100. Lukas M, Neumann ID. Social preference and maternal defeatinduced social avoidance in virgin female rats: sex differences in involvement of brain oxytocin and vasopressin. J Neurosci Methods. 2014;234:101-7.

101. Deisseroth K. Optogenetics. Nat Methods. 2011;8:26-29.

102. Grund T, Tang Y, Benusiglio D, Althammer F, Probst S, Oppenlander L, et al. Chemogenetic activation of oxytocin neurons: Temporal dynamics, hormonal release, and behavioral consequences. Psychoneuroendocrinology. 2019;106:77-84.

103. Choe HK, Reed MD, Benavidez N, Montgomery D, Soares N, Yim YS, et al. Oxytocin mediates entrainment of sensory stimuli to social cues of opposing valence. Neuron. 2015;87:152-63.

104. Jameson H, Bateman R, Byrne P, Dyavanapalli J, Wang X, Jain $\mathrm{V}$, et al. Oxytocin neuron activation prevents hypertension that occurs with chronic intermittent hypoxia/hypercapnia in rats. Am J Physiol Heart Circ Physiol. 2016;310:H1549-1557.

105. Xiao L, Priest MF, Nasenbeny J, Lu T, Kozorovitskiy Y. Biased oxytocinergic modulation of midbrain dopamine systems. Neuron. 2017;95:368-84.e5.

106. Benveniste H, Huttemeier PC. Microdialysis-theory and application. Prog Neurobiol. 1990;35:195-215.

107. Wei D, Lee D, Cox CD, Karsten CA, Penagarikano O, Geschwind $\mathrm{DH}$, et al. Endocannabinoid signaling mediates oxytocin-driven social reward. Proc Natl Acad Sci USA. 2015;112:14084-9.

108. Stachniak TJ, Ghosh A, Sternson SM. Chemogenetic synaptic silencing of neural circuits localizes a hypothalamus->midbrain pathway for feeding behavior. Neuron. 2014;82:797-808.

109. Leng G, Ludwig M. Intranasal oxytocin: myths and delusions. Biol Psychiatry. 2016;79:243-50.

110. Huang H, Michetti C, Busnelli M, Manago F, Sannino S, Scheggia D, et al. Chronic and acute intranasal oxytocin produce divergent social effects in mice. Neuropsychopharmacology. 2014;39:1102-14.

111. Peters S, Slattery DA, Uschold-Schmidt N, Reber SO, Neumann ID. Dose-dependent effects of chronic central infusion of oxytocin on anxiety, oxytocin receptor binding and stress-related parameters in mice. Psychoneuroendocrinology. 2014;42:225-36.

112. Mamrut S, Harony H, Sood R, Shahar-Gold H, Gainer H, Shi YJ, et al. DNA methylation of specific $\mathrm{CpG}$ sites in the promoter 
region regulates the transcription of the mouse oxytocin receptor. PLoS ONE. 2013;8:e56869.

113. Choi JW, Kang SM, Lee Y, Hong SH, Sanek NA, Young WS, et al. MicroRNA profiling in the mouse hypothalamus reveals oxytocin-regulating microRNA. J Neurochem. 2013;126:331-7.

114. Choleris E, Gustafsson JA, Korach KS, Muglia LJ, Pfaff DW, Ogawa $\mathrm{S}$. An estrogen-dependent four-gene micronet regulating social recognition: a study with oxytocin and estrogen receptoralpha and -beta knockout mice. Proc Natl Acad Sci USA. 2003;100:6192-7.

115. Sharma D, Handa RJ, Uht RM. The ERbeta ligand 5alphaandrostane, 3beta,17beta-diol (3beta-diol) regulates hypothalamic oxytocin (Oxt) gene expression. Endocrinology. 2012;153: 2353-61.

116. Young LJ, Wang Z, Donaldson R, Rissman EF. Estrogen receptor alpha is essential for induction of oxytocin receptor by estrogen. Neuroreport. 1998;9:933-6.

117. Busnelli M, Chini B. Molecular basis of oxytocin receptor signalling in the brain: what we know and what we need to know. Curr Top Behav Neurosci. 2018;35:3-29.

118. Smith CJ, Poehlmann ML, Li S, Ratnaseelan AM, Bredewold R, Veenema AH. Age and sex differences in oxytocin and vasopressin V1a receptor binding densities in the rat brain: focus on the social decision-making network. Brain Struct Funct. 2017;222:981-1006.

119. Lukas M, Bredewold R, Neumann ID, Veenema AH. Maternal separation interferes with developmental changes in brain vasopressin and oxytocin receptor binding in male rats. Neuropharmacology. 2010;58:78-87.

120. Slattery DA, Uschold N, Magoni M, Bar J, Popoli M, Neumann ID, et al. Behavioural consequences of two chronic psychosocial stress paradigms: anxiety without depression. Psychoneuroendocrinology. 2012;37:702-14.

121. Guzman YF, Tronson NC, Jovasevic V, Sato K, Guedea AL, Mizukami H, et al. Fear-enhancing effects of septal oxytocin receptors. Nat Neurosci. 2013;16:1185-7.

122. Ziegler C, Dannlowski U, Brauer D, Stevens S, Laeger I, Wittmann $\mathrm{H}$, et al. Oxytocin receptor gene methylation: converging multilevel evidence for a role in social anxiety. Neuropsychopharmacology. 2015;40:1528-38.

123. van den Burg EH, Neumann ID. Bridging the gap between GPCR activation and behaviour: oxytocin and prolactin signalling in the hypothalamus. J Mol Neurosci. 2011;43:200-8.

124. Viero CSI, Kitamura N, Verkhratsky A, Fujihara H, Katoh A, Ueta Y, et al. REVIEW: oxytocin: crossing the bridge between basic science and pharmacotherapy. CNS Neurosci Ther. 2010; 16:e138-156.

125. Blume A, Bosch OJ, Miklos S, Torner L, Wales L, Waldherr M, et al. Oxytocin reduces anxiety via ERK1/2 activation: local effect within the rat hypothalamic paraventricular nucleus. Eur J Neurosci. 2008;27:1947-56.

126. van den Burg EH, Stindl J, Grund T, Neumann ID, Strauss O. Oxytocin stimulates extracellular $\mathrm{Ca}$ influx through TRPV2 channels in hypothalamic neurons to exert its anxiolytic effects. Neuropsychopharmacology. 2015;40:2938-47.

127. Jurek B, Slattery DA, Maloumby R, Hillerer K, Koszinowski S, Neumann ID, et al. Differential contribution of hypothalamic MAPK activity to anxiety-like behaviour in virgin and lactating rats. PLoS ONE. 2012;7:e37060.

128. Tomizawa K, Iga N, Lu YF, Moriwaki A, Matsushita M, Li ST, et al. Oxytocin improves long-lasting spatial memory during motherhood through MAP kinase cascade. Nat Neurosci. 2003; 6:384-90.

129. Bakos J, Lestanova Z, Strbak V, Havranek T, Bacova Z. Neonatal manipulation of oxytocin prevents lipopolysaccharideinduced decrease in gene expression of growth factors in two developmental stages of the female rat. Neuropeptides. 2014;48: 281-6.

130. Havranek T, Zatkova M, Lestanova Z, Bacova Z, Mravec B, Hodosy $\mathrm{J}$, et al. Intracerebroventricular oxytocin administration in rats enhances object recognition and increases expression of neurotrophins, microtubule-associated protein 2, and synapsin I. J Neurosci Res. 2015;93:893-901.

131. Martinetz S, Meinung CP, Jurek B, von Schack D, van den Burg EH, Slattery DA, et al. De novo protein synthesis mediated by the eukaryotic elongation factor 2 is required for the anxiolytic effect of oxytocin. Biol Psychiatry. 2019;85:802-11.

132. Freeman SM, Young LJ. Comparative perspectives on oxytocin and vasopressin receptor research in rodents and primates: translational implications. J Neuroendocrinol. 2016;28. https:// doi.org/10.1111/jne.12382.

133. Grinevich V, Stoop R. Interplay between oxytocin and sensory systems in the orchestration of socio-emotional behaviors. Neuron. 2018;99:887-904.

134. Quintana DS, Rokicki J, van der Meer D, Alnaes D, Kaufmann T, Cordova-Palomera A, et al. Oxytocin pathway gene networks in the human brain. Nat Commun. 2019;10:668.

135. Merkle FT, Maroof A, Wataya T, Sasai Y, Studer L, Eggan K, et al. Generation of neuropeptidergic hypothalamic neurons from human pluripotent stem cells. Development. 2015;142:633-43.

136. Garrison JL, Macosko EZ, Bernstein S, Pokala N, Albrecht DR, Bargmann CI. Oxytocin/vasopressin-related peptides have an ancient role in reproductive behavior. Science. 2012;338:540-3.

137. Andari E, Hurlemann R, Young LJ. A precision medicine approach to oxytocin trials. Curr Top Behav Neurosci. 2018;35: 559-90.

138. Herpertz SC, Bertsch K. A new perspective on the pathophysiology of borderline personality disorder: a model of the role of oxytocin. Am J Psychiatry. 2015;172:840-51.

139. Feifel D, Shilling PD, MacDonald K. A review of oxytocin's effects on the positive, negative, and cognitive domains of schizophrenia. Biol Psychiatry. 2016;79:222-33.

140. Domes G, Lischke A, Berger C, Grossmann A, Hauenstein K, Heinrichs M, et al. Effects of intranasal oxytocin on emotional face processing in women. Psychoneuroendocrinology. 2010;35:83-93.

141. Guastella AJ, MacLeod C. A critical review of the influence of oxytocin nasal spray on social cognition in humans: evidence and future directions. Horm Behav. 2012;61:410-8.

142. Brambilla M, Manenti R, de Girolamo G, Adenzato M, BocchioChiavetto L, Cotelli M. Effects of intranasal oxytocin on longterm memory in healthy humans: a systematic review. Drug Dev Res. 2016;77:479-88.

143. Kirsch P, Esslinger C, Chen Q, Mier D, Lis S, Siddhanti S, et al. Oxytocin modulates neural circuitry for social cognition and fear in humans. J Neurosci. 2005;25:11489-93.

144. Petrovic P, Kalisch R, Singer T, Dolan RJ. Oxytocin attenuates affective evaluations of conditioned faces and amygdala activity. J Neurosci. 2008;28:6607-15.

145. Barraza JA, Zak PJ. Empathy toward strangers triggers oxytocin release and subsequent generosity. Ann N Y Acad Sci. 2009; 1167:182-9.

146. Hurlemann R, Patin A, Onur OA, Cohen MX, Baumgartner T, Metzler $\mathrm{S}$, et al. Oxytocin enhances amygdala-dependent, socially reinforced learning and emotional empathy in humans. J Neurosci. 2010;30:4999-5007.

147. Kosfeld M, Heinrichs M, Zak PJ, Fischbacher U, Fehr E. Oxytocin increases trust in humans. Nature. 2005;435:673-6.

148. De Dreu CK, Greer LL, Van Kleef GA, Shalvi S, Handgraaf MJ. Oxytocin promotes human ethnocentrism. Proc Natl Acad Sci USA. 2011;108:1262-6.

149. Marsh N, Scheele D, Feinstein JS, Gerhardt H, Strang S, Maier W, et al. Oxytocin-enforced norm compliance reduces 
xenophobic outgroup rejection. Proc Natl Acad Sci USA. 2017;114:9314-9.

150. Eckstein M, Becker B, Scheele D, Scholz C, Preckel K, Schlaepfer TE, et al. Oxytocin facilitates the extinction of conditioned fear in humans. Biol Psychiatry. 2015;78:194-202.

151. Neumann ID, Maloumby R, Beiderbeck DI, Lukas M, Landgraf $\mathrm{R}$. Increased brain and plasma oxytocin after nasal and peripheral administration in rats and mice. Psychoneuroendocrinology. 2013;38:1985-93.

152. Tzabazis A, Kori S, Mechanic J, Miller J, Pascual C, Manering N, et al. Oxytocin and migraine headache. Headache. 2017;57:64-75.

153. Lee MR, Scheidweiler KB, Diao XX, Akhlaghi F, Cummins A, Huestis MA, et al. Oxytocin by intranasal and intravenous routes reaches the cerebrospinal fluid in rhesus macaques: determination using a novel oxytocin assay. Mol Psychiatry. 2018;23:115-22.

154. Striepens N, Kendrick KM, Hanking V, Landgraf R, Wullner U, Maier W, et al. Elevated cerebrospinal fluid and blood concentrations of oxytocin following its intranasal administration in humans. Sci Rep. 2013;3:3440.

155. Born J, Lange T, Kern W, McGregor GP, Bickel U, Fehm HL. Sniffing neuropeptides: a transnasal approach to the human brain. Nat Neurosci. 2002;5:514-6.

156. Lee MRST, Blue SW, Kaucher AV, Winchell AJ, Erikson DW, Grant KA, et al. Labelled oxytocin administered via the intranasal route reaches the brain in rhesus macaques. Nat Commun. 2020 (in press).

157. Paloyelis Y, Doyle OM, Zelaya FO, Maltezos S, Williams SC, Fotopoulou A, et al. A spatiotemporal profile of in vivo cerebral blood flow changes following intranasal oxytocin in humans. Biol Psychiatry. 2016;79:693-705.

158. Walum H, Waldman ID, Young LJ. Statistical and methodological considerations for the interpretation of intranasal oxytocin studies. Biol Psychiatry. 2016;79:251-7.

159. Quintana DS, Alvares GA, Hickie IB, Guastella AJ. Do delivery routes of intranasally administered oxytocin account for observed effects on social cognition and behavior? A two-level model. Neurosci Biobehav Rev. 2015;49:182-92.

160. Verhees M, Houben J, Ceulemans E, Bakermans-Kranenburg MJ, van IMH, Bosmans G. No side-effects of single intranasal oxytocin administration in middle childhood. Psychopharmacology. 2018;235:2471-7.

161. MacDonald E, Dadds MR, Brennan JL, Williams K, Levy F, Cauchi AJ. A review of safety, side-effects and subjective reactions to intranasal oxytocin in human research. Psychoneuroendocrinology. 2011;36:1114-26.

162. Bales KL, Perkeybile AM, Conley OG, Lee MH, Guoynes CD, Downing GM, et al. Chronic intranasal oxytocin causes longterm impairments in partner preference formation in male prairie voles. Biol Psychiatry. 2013;74:180-8.

163. Pagani M, De Felice A, Montani C, Galbusera A, Papaleo F, Gozzi A. Acute and repeated intranasal oxytocin differentially modulate brain-wide functional connectivity. Neuroscience. 2020. https://doi.org/10.1016/j.neuroscience.2019.12.036.

164. Rasmussen MS, Simonsen JA, Sandgaard NC, Hoilund-Carlsen PF, Bie P. Effects of oxytocin in normal man during low and high sodium diets. Acta Physiol Scand. 2004;181:247-57.

165. Norman GJ, Cacioppo JT, Morris JS, Malarkey WB, Berntson GG, Devries AC. Oxytocin increases autonomic cardiac control: moderation by loneliness. Biol Psychol. 2011;86:174-80.

166. Tops S, Habel U, Radke S. Genetic and epigenetic regulatory mechanisms of the oxytocin receptor gene (OXTR) and the (clinical) implications for social behavior. Horm Behav. 2019; 108:84-93.

167. Ebstein RP, Israel S, Chew SH, Zhong S, Knafo A. Genetics of human social behavior. Neuron. 2010;65:831-44.
168. van Roekel E, Verhagen M, Scholte RHJ, Kleinjan M, Goossens L, Engels RCME. The Oxytocin Receptor Gene (OXTR) in relation to state levels of loneliness in adolescence: evidence for micro-level gene-environment interactions. PLoS ONE. 2013; 8.

169. Haram M, Tesli M, Bettella F, Djurovic S, Andreassen OA, Melle I. Association between genetic variation in the oxytocin receptor gene and emotional withdrawal, but not between oxytocin pathway genes and diagnosis in psychotic disorders. Front Hum Neurosci. 2015;9:9.

170. Tost H, Kolachana B, Hakimi S, Lemaitre H, Verchinski BA, Mattay VS, et al. A common allele in the oxytocin receptor gene (OXTR) impacts prosocial temperament and human hypothalamiclimbic structure and function. Proc Natl Acad Sci USA. 2010; 107:13936-41.

171. Kim HS, Sherman DK, Sasaki JY, Xu J, Chu TQ, Ryu C, et al. Culture, distress, and oxytocin receptor polymorphism (OXTR) interact to influence emotional support seeking. Proc Natl Acad Sci USA. 2010;107:15717-21.

172. Rodrigues SM, Saslow LR, Garcia N, John OP, Keltner D. Oxytocin receptor genetic variation relates to empathy and stress reactivity in humans. Proc Natl Acad Sci USA. 2009;106: 21437-41.

173. Bakermans-Kranenburg MJ, van Ijzendoorn MH. Oxytocin receptor (OXTR) and serotonin transporter (5-HTT) genes associated with observed parenting. Soc Cogn Affect Neurosci. 2008;3:128-34.

174. Gregory SG, Connelly JJ, Towers AJ, Johnson J, Biscocho D, Markunas CA, et al. Genomic and epigenetic evidence for oxytocin receptor deficiency in autism. BMC Med. 2009;7:62.

175. Waltenspühl YSJ, Ehrenmann J, Kummer L, Plückthun A. Crystal structure of the human oxytocin receptor. 2020. https://www.biorxiv.org/content/10.1101/2020.02.21.958090v1.

176. de Jong TR, Menon R, Bludau A, Grund T, Biermeier V, Klampfl SM, et al. Salivary oxytocin concentrations in response to running, sexual self-stimulation, breastfeeding and the TSST: the Regensburg Oxytocin Challenge (ROC) study. Psychoneuroendocrinology. 2015;62:381-8.

177. Nagasawa M, Mitsui S, En S, Ohtani N, Ohta M, Sakuma Y, et al. Social evolution. Oxytocin-gaze positive loop and the coevolution of human-dog bonds. Science. 2015;348:333-6.

178. Neumann I, Landgraf R, Takahashi Y, Pittman QJ, Russell JA. Stimulation of oxytocin release within the supraoptic nucleus and into blood by CCK-8. Am J Physiol. 1994;267:R1626-1631.

179. Sabatier N, Caquineau C, Dayanithi G, Bull P, Douglas AJ, Guan XM, et al. Alpha-melanocyte-stimulating hormone stimulates oxytocin release from the dendrites of hypothalamic neurons while inhibiting oxytocin release from their terminals in the neurohypophysis. J Neurosci. 2003;23:10351-8.

180. Prescott JH, Lipka S, Baldwin S, Sheppard NF Jr., Maloney JM, Coppeta J, et al. Chronic, programmed polypeptide delivery from an implanted, multireservoir microchip device. Nat Biotechnol. 2006;24:437-8.

181. Andari E, Duhamel JR, Zalla T, Herbrecht E, Leboyer M, Sirigu A. Promoting social behavior with oxytocin in high-functioning autism spectrum disorders. Proc Natl Acad Sci USA. 2010;107: 4389-94.

182. Hollander E, Bartz J, Chaplin W, Phillips A, Sumner J, Soorya L, et al. Oxytocin increases retention of social cognition in autism. Biol Psychiatry. 2007;61:498-503.

183. Hollander E, Novotny S, Hanratty M, Yaffe R, DeCaria CM, Aronowitz BR, et al. Oxytocin infusion reduces repetitive behaviors in adults with autistic and Asperger's disorders. Neuropsychopharmacology. 2003;28:193-8.

184. Flanagan JC, Sippel LM, Wahlquist A, Moran-Santa Maria MM, Back SE. Augmenting Prolonged Exposure therapy for PTSD 
with intranasal oxytocin: a randomized, placebo-controlled pilot trial. J Psychiatr Res. 2018;98:64-69.

185. Frijling JL, van Zuiden M, Koch SB, Nawijn L, Goslings JC, Luitse JS, et al. Efficacy of oxytocin administration early after psychotrauma in preventing the development of PTSD: study protocol of a randomized controlled trial. BMC Psychiatry. 2014;14:92.

186. Olff M, Langeland W, Witteveen A, Denys D. A psychobiological rationale for oxytocin in the treatment of posttraumatic stress disorder. CNS Spectr. 2010;15:522-30.

187. Fudge N, Sadler E, Fisher HR, Maher J, Wolfe CD, McKevitt C. Optimising translational research opportunities: a systematic review and narrative synthesis of basic and clinician scientists' perspectives of factors which enable or hinder translational research. PLoS ONE. 2016;11:e0160475.

188. Yu D. Translational research: current status, challenges and future strategies. Am J Transl Res. 2011;3:422-33.

189. Holmes EA, O'Connor RC, Perry VH, Tracey I, Wessely S, Arseneault L, et al. Multidisciplinary research priorities for the COVID-19 pandemic: a call for action for mental health science. Lancet Psychiatry. 2020;7:547-60.

190. MORI I. COVID-19 and mental wellbeing. Ipsos MORI. 2020. https://www.ipsos.com/ipsos-mori/en-uk/Covid-19-and-menta l-wellbeing.

191. Heck AL, Sheng JA, Miller AM, Stover SA, Bales NJ, Tan SML, et al. Social isolation alters hypothalamic pituitary adrenal axis activity after chronic variable stress in male C57BL/6 mice. Stress. 2020:1-9. https://doi.org/10.1080/10253890.2020.1733962.
192. Ross AP, McCann KE, Larkin TE, Song Z, Grieb ZA, Huhman $\mathrm{KL}$, et al. Sex-dependent effects of social isolation on the regulation of arginine-vasopressin (AVP) V1a, oxytocin (OT) and serotonin $(5 \mathrm{HT})$ 1a receptor binding and aggression. Horm Behav. 2019;116:104578.

193. Kikusui T, Winslow JT, Mori Y. Social buffering: relief from stress and anxiety. Philos Trans R Soc Lond B Biol Sci. 2006; 361:2215-28.

194. Knox SS, Uvnas-Moberg K. Social isolation and cardiovascular disease: an atherosclerotic pathway? Psychoneuroendocrinology. 1998;23:877-90.

195. DeVries AC, Craft TK, Glasper ER, Neigh GN, Alexander JK, Curt P. Richter award winner: social influences on stress responses and health. Psychoneuroendocrinology. 2006;32:587-603. 2007.

196. Riem MME, Kunst LE, Bekker MHJ, Fallon M, Kupper N. Intranasal oxytocin enhances stress-protective effects of social support in women with negative childhood experiences during a virtual Trier Social Stress Test. Psychoneuroendocrinology. 2020;111:104482.

197. Tsai TY, Tseng HH, Chi MH, Chang HH, Wu CK, Yang YK, et al. The interaction of oxytocin and social support, loneliness, and cortisol level in major depression. Clin Psychopharmacol Neurosci. 2019;17:487-94.

198. Heinrichs M, Baumgartner T, Kirschbaum C, Ehlert U. Social support and oxytocin interact to suppress cortisol and subjective responses to psychosocial stress. Biol Psychiatry. 2003;54:1389-98. 